Article

\title{
Rural-Urban Transition in Central Java: Population and Economic Structural Changes Based on Cluster Analysis
}

\author{
Wiwandari Handayani \\ Department of Urban and Regional Planning, Diponegoro University, Semarang 50275, Indonesia; \\ E-Mail: wiwandari.handayani@undip.ac.id; Tel./Fax: +62-24-764-80-856
}

Received: 20 June 2013; in revised form: 12 July 2013 / Accepted: 1 August 2013 /

Published: 16 August 2013

\begin{abstract}
In Central Java, in addition to the traditional view of urban transition as an aspect of urban industrialization, rural industrialization based on small- to medium-sized enterprises has become a concern, at least since the Indonesian economic crisis in 1997. Combinations of typical urban and rural activities have resulted in certain features of rural-urban transition as the urban population has continued to increase notably. The intention of this paper is to examine how rural-urban transition characterizes the industrialization of Central Java. Multivariate cluster analysis is applied to create a typology, with the district as the unit of analysis, to better understand the transition phenomenon in terms of the population and economic structure. The cluster solution shows that rural-urban transition occurs on at least two different paths. The first path could be described as industrialization from above, in which the transition takes place as a part of the urban growth process. The second path could be described as industrialization from below, in which rapid industrialization occurs far from the highest hierarchy of the urban center.
\end{abstract}

Keywords: rural-urban transition; urbanization; industrialization; Central Java; cluster analysis

\section{Introduction}

Urbanization is credited with responsibility for various phenomena. Urbanization may be viewed simply as a demographic phenomenon. Economic and social changes are also sometimes considered to be consequences of urbanization. In general, urbanization can be equated with modernization, as well as transformation in a development context [1]. Development associated with urbanization is 
inextricably related to the transitions between rural and urban areas or, in other words, the processes of urban changes and rural changes [2]. From this perspective, transition can be viewed as a form of urban development and rural development, involving transformation from rural to urban features.

Particularly in most of the developing countries in Asia, urban transition is strongly related to international capitalism. Gilbert and Gugler [3] called this peripheral urbanization. In this form of urbanization, multinational corporations play a significant role in forcing the development of large urban areas. Evidence of this influence is the fact that manufacturing industries mostly based on foreign investment have become engines of growth in many large cities in Asia, at least since the end of World War II. These industries have attracted laborers to move either from rural or lower-hierarchy urban centers to higher-hierarchy or larger urban areas. Moreover, to achieve good economic performance, governments in most of Asia's developing countries are likely to prioritize physical infrastructure development in large urban centers over infrastructure development in smaller cities and rural areas. As explained by the growth centers (unbalanced development) theory proposed by Hirchman (1958), Myrdal (1957) and Perroux (1955), the development of these centers is expected to spread to the surrounding regions [4]. However, what has happened is the reverse. The centers are likely to absorb most potential resources, mainly laborers and natural resources, from their surrounding rural areas and lower-hierarchy urban regions. Accordingly, disparity and equality have remained central issues to be resolved, in addition to the existence of the informal sector in most urban areas in Asia. These informal sectors have appeared mainly due to the lack of work opportunities in the urban centers compared to the number of workers who seek jobs in these areas [5].

In Central Java, in addition to the traditional view of urban transition as an aspect of urban industrialization, rural industrialization based on small- to medium-sized enterprises has become a concern, at least since the Indonesian economic crisis in 1997. As discussed by Hill [6], high dependency on foreign investment hit the Indonesian economy hard during the crisis. The government had been providing ample space for foreign stakeholders to play a significant role in the industrialization of the country. These open economic policies, however, were not matched by strong performance in institutional development to maintain policies for enhancing necessary initiatives for long-term industrialization. As a result, many large foreign-based enterprises located in urban areas collapsed, while, as Tambunan [7] showed, small- to medium-sized enterprises played a dominant role in the usage of local resources, and their flexibility in production processes produced the steadiest growth during the crisis period.

Rural industrialization has resulted in various typically urban activities taking place in an area officially defined as rural. This industrialization is expected to generate strong economic links between rural and urban areas, as well as with the world market. Qadeer [8] showed that there are many rural regions in Asia with density and settlement systems with urban characteristics. He describes this as "urbanization by implosion". From an urban hierarchical perspective, these areas are located relatively far from large urban centers, and most of the time, they are classified as remote areas. The centers of their development are obviously not large urban centers. McGee, in Forbes [9], explains these "wet rice areas" as one form of 'endogenous urbanization.'

Combinations of typical urban and rural activities have resulted in certain features of rural-urban transition, as the urban population has continued to increase notably in various ways in Java. Meanwhile, most research on rural-urban transition is focused only on particular aspects, such as the 
movement of people and the flow of natural resources. Migration and agricultural issues have become the focus of matters in current rural-urban discourse [10-12]. There is still little discussion of comprehensive features of the rural-urban transition process. The purpose of this paper is to examine how rural-urban transition characterizes the urbanization of Central Java, using variables representing various aspects of that transition. Multivariate cluster analysis is applied to create a typology to better understand the transition phenomenon.

This paper is organized into four sections. Section 1 is an introduction that explains the rationale for this study. Section 2 briefly explains the study area, data needs and the steps in the cluster analysis. Section 3 presents the results and interpretation of the cluster analysis as the main statistical tool used to classify rural-urban regions, followed by a discussion of rural-urban transition in terms of population and economic structure. Section 4 concludes with some remarks concerning rural-urban transition in the study area.

\section{Data and Methods}

\subsection{Study Area and Data Needs}

The study area is located within the administrative boundary of Central Java Province in Indonesia. It is located on Java Island and consists of 35 districts/municipalities. The total area of the province is 3.25 million hectares, and the total population is 32.18 million persons or approximately 14 percent of the Indonesian population (Central Bureau of Statistics (CBS), 2006 [13]). In general, urbanization in Central Java Province has not been remarkable compared to other provinces on Java Island. Located between two large provinces, namely, West Java and East Java, 35 percent of the area is moderately hilly, and a significant portion of the area of the province is an agriculture protection zone. These features have limited the development of the province. Figure 1 shows that the urban proportion of the population in Central Java Province is the lowest of any province on Java Island, slightly lower than that of East Java, which has reached 48.9 percent. Along with the urban proportion of the population, the population density in Central Java Province is also reasonably low compared to other provinces on the island (see Figure 2).

Figure 1. Urban population on Java Island, 2005. Source: CBS, 2005 [14].

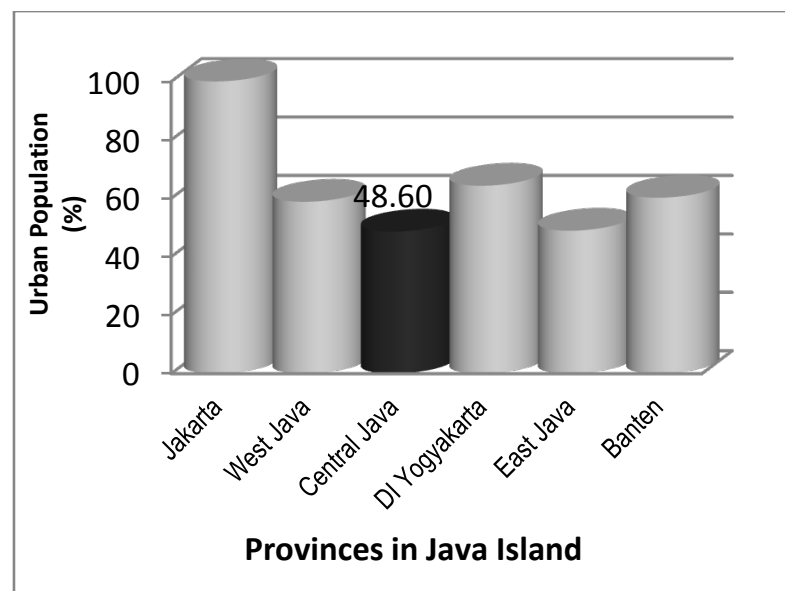


As the study area is within the provincial boundaries, one lower administrative level, i.e., the district, was used as the analysis unit in the clustering process. All data employed in this research are secondary data from annual statistical reports and relevant publications based on census and survey data from the Central Bureau of Statistics (CBS). Variables were selected using a deductive approach based strongly on the literature. In general, the variables are divided into three categories, namely, physical environment, economic and sociopolitical variables. The variables are classified as static if they are only based on one specific period (i.e., 2006) and dynamic if changes between two time series are indicated (i.e., 1994 and 2006).

Figure 2. Population density on Java Island, 2006. Source: CBS, 2006 [13].

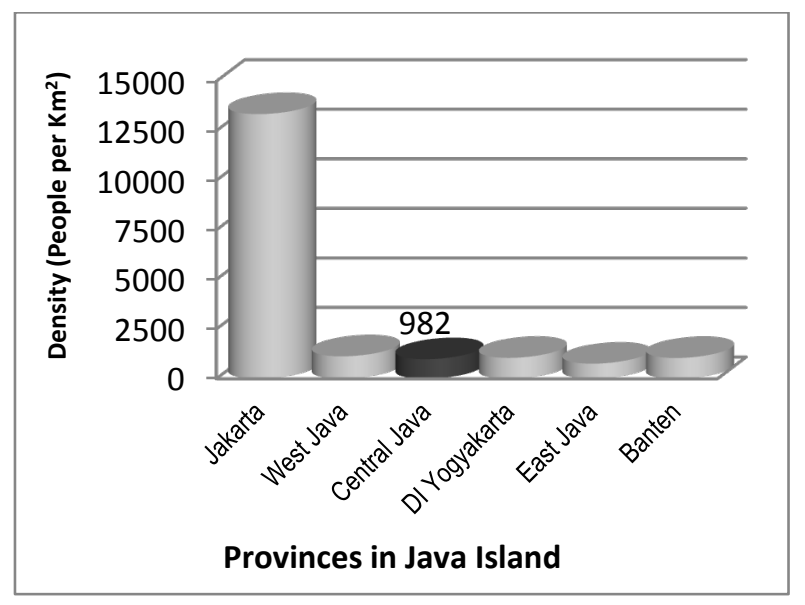

\subsection{Methods: Applying a Cluster Analysis to Create a Rural-Urban Typology for Central Java}

Cluster analysis is a multivariate statistical approach for grouping data. Each group (cluster) contains sets of cases that are similar in character. Cluster analysis was applied in creating a rural-urban typology to better understand the rural-urban transition in the study area. To build the typology, there are considerably large data sets (variables) that need to be classified into groups, based on their similarity. Applying clustering algorithms helps to organize the data into groups efficiently, based on a statistical formulation. This organizing process facilitates the discovery of the characteristics of each group.

Several steps were necessary to create a typology using cluster analysis. A brief explanation of how each step is applied in this research is presented below.

1. Assessment of the variables. This includes selection of variables and examination of data quality. A stepwise analysis is used to examine the quality of the data. The analysis is mainly derived from the following:

- Calculation of the range, standard deviation, variance, skewness and kurtosis of the variables. These statistical measures are used to analyze the distribution of the data and to identify outliers.

- Matrix correlation to minimize multicollinearity. 
2. Clustering of the algorithm selection. Clustering was used to produce the most expected cluster. As there is no agreement as to which is the best algorithm to be used, a comparison of all possible algorithms with all possible distance measurements was applied.

After comparing the methods of hierarchical clustering with single linkage, complete-linkage clustering, group-average clustering, centroid clustering, median clustering, Wards' clustering and K-means (non-hierarchical) clustering, it was determined that Ward's method, with its squared Euclidian distance and z-score standardization, was the best suited to the purpose of this research. A number of previous research projects using cluster analyses also highlight the efficiency of Ward's method compared to other methods [15-18]. Figure 4a shows a dendrogram of the final results of the cluster analysis, obtained using Predictive Analytics SoftWare (PASW) Statistics 18. The z-score was used as the common method of standardization in applying Ward's hierarchical method. In principal, z-score standardization weighs each value of variable $X i$ against the mean of variable $X$. The result is then divided by the standard deviation of each variable, $\sigma$ (see Equation (1)).

$$
\mathrm{Z}=(\mathrm{Xi}-\mathrm{X}) / \sigma
$$

One important assumption in applying z-score standardization is that the data should be normally distributed [19]. This may also explain why the variable assessment in the previous step includes assessment of parameters of the distribution of the data.

To determine how "close" or how "far" cases in the cluster are from each other, the squared Euclidian distance method was applied. The squared Euclidian distance formula is the most commonly used method for continuous data [16]. In addition, this calculation is highly recommended for use with Ward's hierarchical methods $[16,19]$.

3. Validation. To check the validity of the dendrogram, two types of discriminant analysis are used. The first type involves applying all the variables to the analysis. The second type involves using a stepwise approach in which only selected variables are used to validate the clustering results. As Huberty [20] explains, to have a valid hit-rate estimation, the number of sample sizes (case $\rightarrow$ districts) should be large enough or at least $n \geq 5 p$, i.e., the number of cases should be at least five times greater than the number of variables. The stepwise approach was used to fulfill this criterion.

It was determined that 100 percent of the original grouped cases were correctly classified by applying all of the variables and that 93.1 percent of the cases were correctly classified using the stepwise approach. These percentages were convincing enough to conclude that the dendrogram had produced its optimum result.

4. Interpretation. In interpreting the clustering results, the urban and rural characteristics of each district were differentiated. Therefore, as explained in the following section, subgroups in the cluster are defined based on a combination of rural and urban characteristics. 


\section{Results and Discussion}

\subsection{Assessment of the Variables}

Initially, there were 35 districts, six urban and 29 non-urban, and 72 variables to be examined. To produce robust and statistically convincing indicators, stepwise analysis was used to examine the quality of the data. The examination consisted of two main steps. The first step involved calculation of the ranges, standard deviations, variances, skewness and kurtosis of the variables. These statistical measures were employed in analyzing the distribution of the data and the identification of outliers. The second step involved using matrix correlation to minimize multicollinearity. In eliminating those variables, the representation of each category is greatly improved. As z-score standardization was applied, only variables found to be normally distributed were chosen. The mean values of the variables ranged from a low of 3.4 (for annual growth of employment engaged in the non-primary sector) to a high of 135.8 (for built-up areas); the skewness and kurtosis values of all the variables chosen were close to zero (ranging from -0.99 to 0.99 ).

However, disparities between urban districts and non-urban districts do exist in the research area; therefore, outliers were significant for several variables. In the first iteration, outliers were identified due to six small areas (categorized as urban districts) contributing significantly to almost all development indicators. These six urban districts were then excluded in the first iteration of variable assessment. Nine variables related to Gross domestic product (GDP), employment and density were eliminated in the second iteration, because of their non-normal distributions (as indicated by skewness and kurtosis values $>0.99$ or $<-0.99$ ) or because they contained outliers. Nevertheless, for the purpose of comprehensive interpretation, the six urban districts that were excluded in the first iteration were still considered in the final interpretation.

Figure 3. Selection of variables by stepwise analysis.

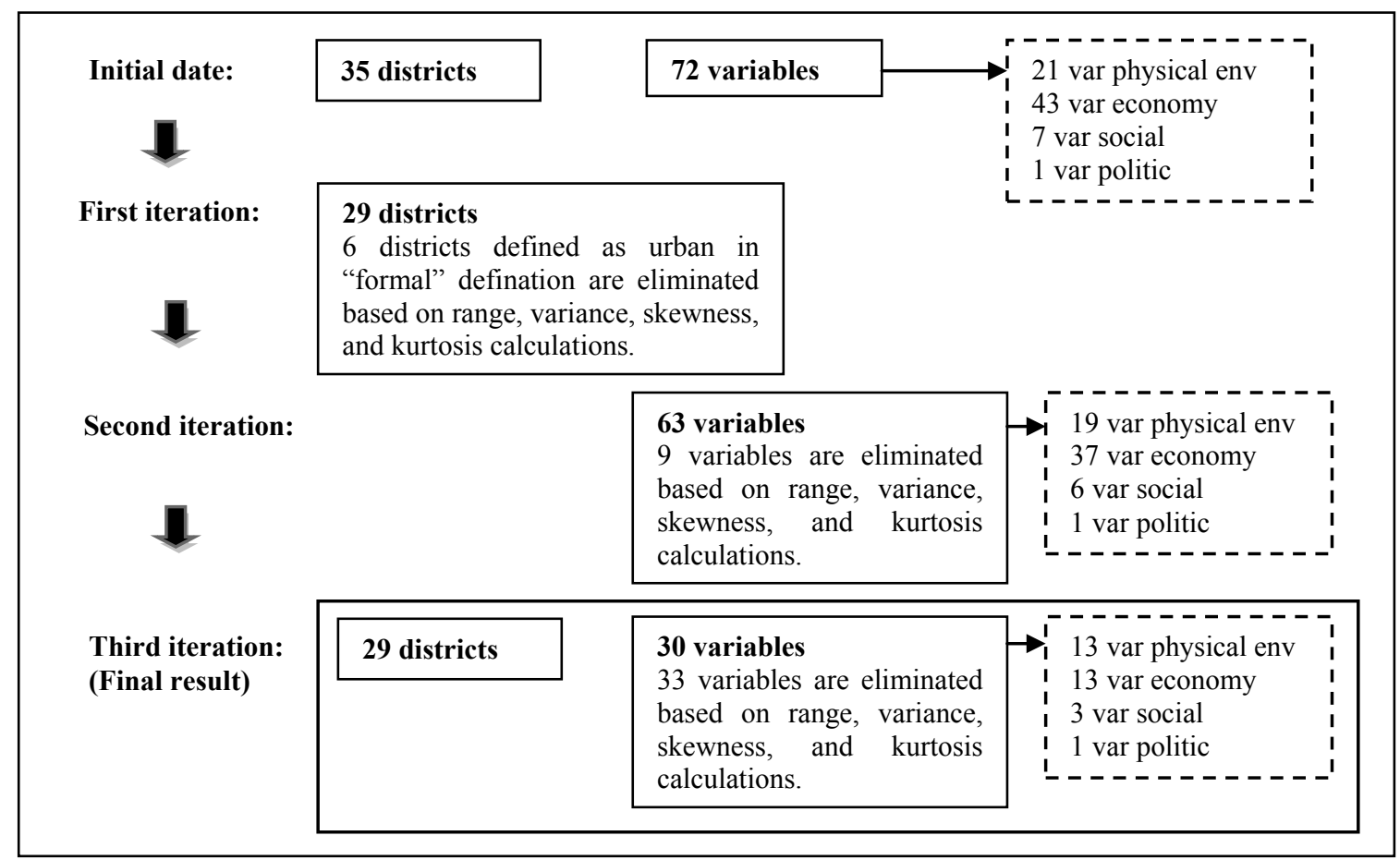


Another issue was multicollinearity, which was inevitable, because many of the variables initially analyzed were likely to have been related. For example, the number of jobs in industries may be highly correlated with the number of industries, and the GDP of the industry also may be highly correlated with the number of large industries. It was also difficult to apply time series data, because, for some variables, such as education attainment, the situation in 1994 was similar to the situation in 2006, as reflected in the relatively high correlation between the two variables. Figure 3 explains the selection process of the variables, and Table 1 shows the list of variables that were finally used in the cluster analysis.

\subsection{Cluster Solution and Dendrogram Interpretation}

From examination of the dendrogram based on the explanation in Table 1, four main groups were identified (see Figures 4 and 5). First, 16 districts were identified as being highly rural. With respect to their physical environment, they are mainly characterized by relatively low proportions of their population categorized as living in urban regions $(<20$ percent), low proportions of built-up areas ( $<25$ percent) and being mostly located in remote and relatively hilly areas, far from the closest growth centers (16-20 km from the closest urban center) and airport facilities (71-190 km from the closest airport facility). Due to these physical limitations, the activity of these districts is dominated by agriculture. In other words, the physical characteristics of these districts do not favor industrial development. These districts also have very low proportions of people who have graduated from high school or university ( $<20$ percent). This low level of education has led to high average unemployment growth (13.30 percent), as well as a low employment rate ( $<60$ percent).

Table 1. Variables to explain the performance of the rural-urban interface in the study area.

\begin{tabular}{|c|c|c|c|}
\hline & Physical Environment & Economic & Social-Politic \\
\hline 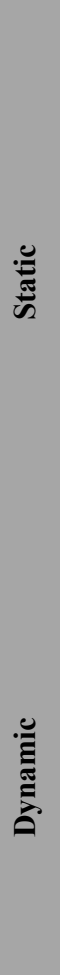 & $\begin{array}{l}\text { - Number of people living in urban areas } \\
\text { - Built-up area }\left(\mathrm{km}^{2}\right) \\
\text { - Average distance to the closest urban } \\
\text { center }(\mathrm{km}) \\
\text { - Average distance to the closest airport } \\
(\mathrm{km}) \\
\text { - Proportion of area }(\%) \text { with zoning } \\
\text { limiting urbanization, including } \\
\text { environmental protection areas, } \\
\text { agricultural protection areas and } \\
\text { disaster-prone areas } \\
\text { - Growth of built-up area }\left(\mathrm{km}^{2}\right)\end{array}$ & $\begin{array}{l}\text { - Contributions of the industrial and service } \\
\text { sectors to GDP (\%) } \\
\text { - Contribution of the industrial and service } \\
\text { sectors to the provincial } \\
\text { GDP (\%) } \\
\text { - Proportion of employment engaged in the } \\
\text { industrial and service } \\
\text { sectors (\%) } \\
\text { - Proportion of employment engaged in the } \\
\text { industrial and service sectors at the } \\
\text { provincial level (\%) } \\
\text { - Annual growth of the non-primary sector in } \\
\text { GDP (\%) } \\
\text { - Growth of the GDP share of the } \\
\text { non-primary sector (\%) } \\
\text { - Annual growth of employment engaged in } \\
\text { the industrial and service sectors (\%) } \\
\text { - Growth of the proportion of employment } \\
\text { engaged in the industrial and service sectors (\% }\end{array}$ & $\begin{array}{l}\text { - Proportion of population that } \\
\text { has graduated from high } \\
\text { school and university (\%) } \\
\text { - Employment rate (\%) } \\
\text { - Political intervention, as } \\
\text { indicated by policy documents } \\
\text { by ranking (dummy variable) }\end{array}$ \\
\hline
\end{tabular}


In addition to the 16 districts characterized above, there are six districts classified as Rural-Urban Type $\mathrm{C}$, which have a character very similar to that of the highly rural districts. These districts may be classified as rural-urban, because of their physical characteristics. High proportions of the populations of these districts are urban (20-40 percent). These districts are not located in remote areas, which means that they are closer to urban centers (11-15 km from the closest urban center) and airport facilities (51-70 km from the closest airport facility) than the highly rural districts, and they are located in flat areas. However, in terms of their economic features, these districts are highly rural and tend to be dominated by agricultural activities.

Figure 4. (a) Cluster solution (final result from Predictive Analytics SoftWare (PASW) 18). (b) Cluster solution (final result from PASW 18).

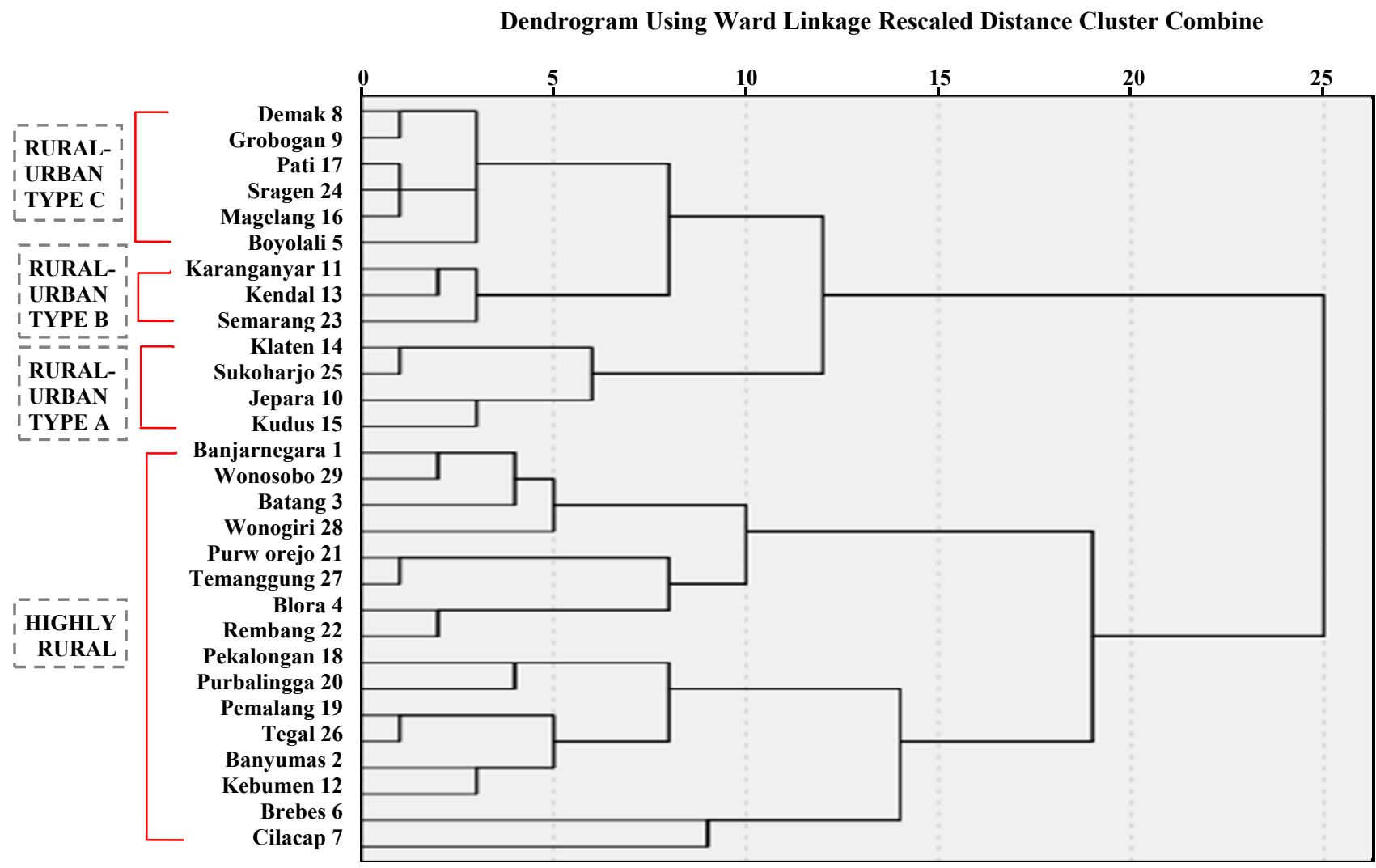

(a)

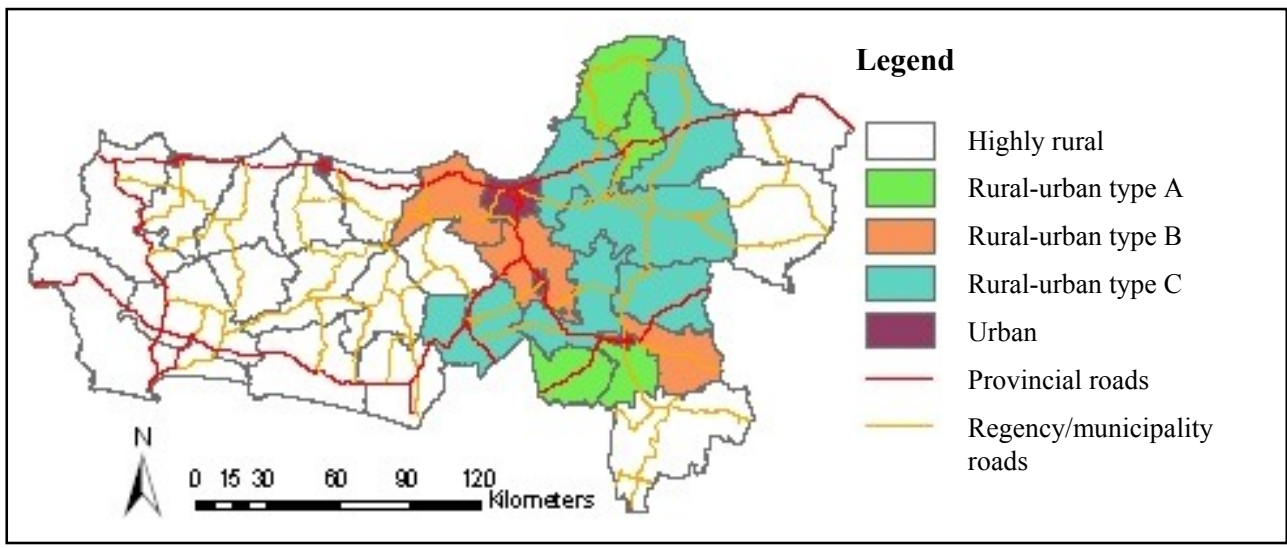

(b) 
The most significant characteristics of the rural-urban regions is evident in seven rural-urban districts classified as Rural-Urban Type A and Type B. The two most obvious indicators are a high contribution of the industrial sector to the GDP and a significant proportion of employment in the non-primary sector. These districts are categorized further into two different groups.

Figure 5. Dendrogram interpretation.

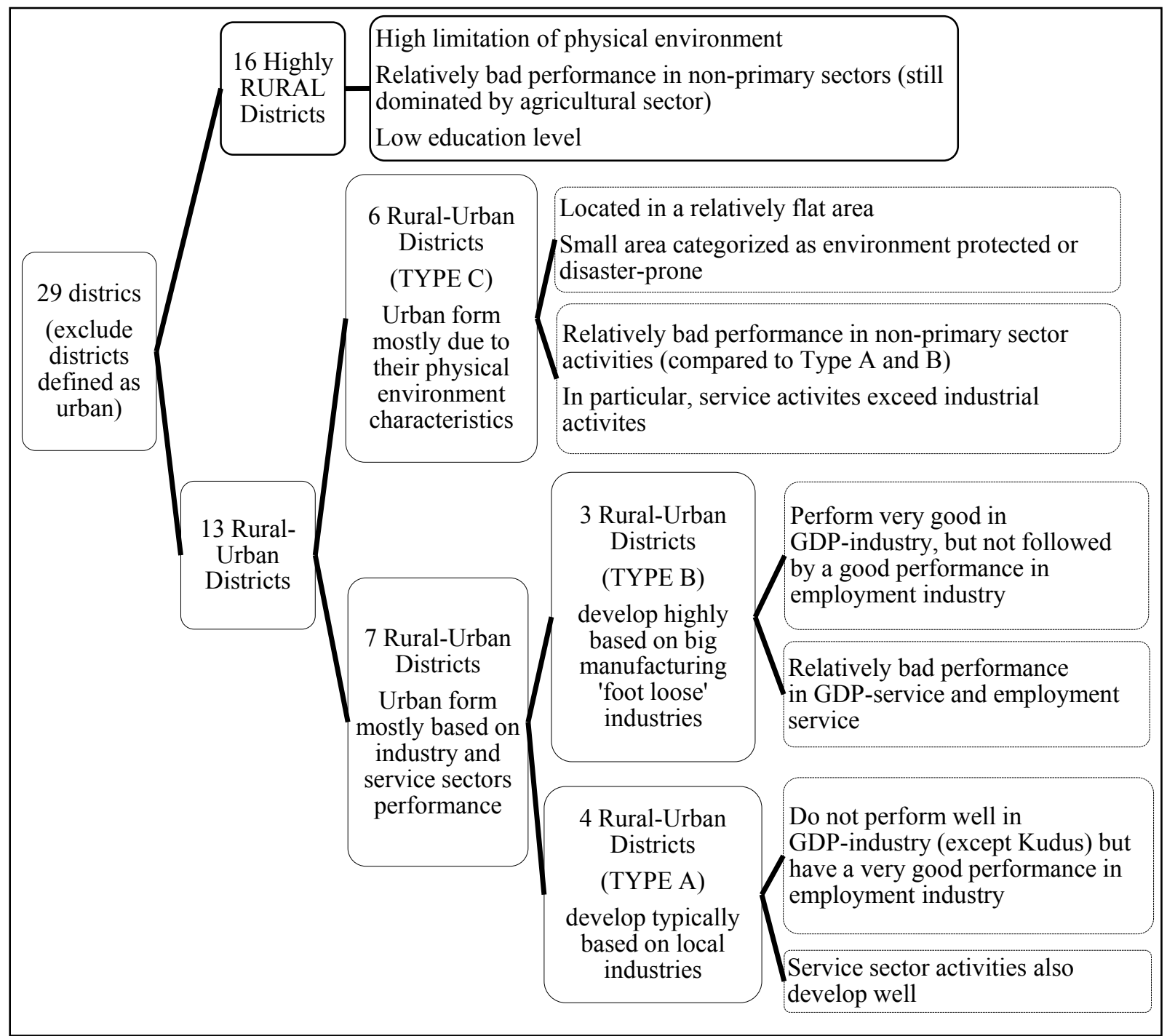

The first group is Rural-Urban Type A, which is characterized by quite significant involvement of smaller industrial activities. This group is mainly characterized by a relatively lower contribution of the industrial sector to GDP (20-30 percent) and a higher proportion of employment in the industrial sector (30-50 percent). These districts are not necessarily located on the urban fringe districts and are not necessarily supported by the political will to develop these districts as centers of growth at the provincial level. The second is Rural-Urban Type B, which is characterized by the dominant role of large manufacturing industries. The dominant features of these districts are a high contribution of the industrial sector to GDP (40-50 percent), with relatively low employment in the industrial sector (15-20 percent), being located in an urban fringe area and being supported by the political will to push for economic growth at the provincial level. 
However, there are some similarities between the Rural-Urban Type A and Type B groups. They both have relatively high proportions of people who have graduated from high school and university, compared to highly rural regions and those in the Rural-Urban Type $\mathrm{C}$ group. They are also located in relatively flat areas and have good access to the closest urban centers and airport facilities. Figure 5 summarizes the dendrogram interpretation.

\subsection{Rural-Urban Transition in Central Java Based on an Examination of Population Changes}

The rural-urban transition process is reflected in the shifting of the population that is defined as living in rural or urban areas. In this research, urban and rural areas are defined on the basis of their CBS classification, which is a function primarily of the population density, the percentage of farming households and accessibility to urban facilities. For each variable, a score $\geq 10$ is classified as urban and $\leq 10$ is classified as rural. For example, a district with a population density $>8,500 / \mathrm{km}^{2}$, a percentage of farming households $<5$ and all households served by electricity and a telephone network and having access to some other main urban facilities would have the highest score. As Table 2 shows, apart from the dominant contribution of the urban population living in urban districts, there is a tendency toward significant urban population growth in Central Java Province as a whole.

The most rapid growth of the urban population took place in the districts in the Rural-Urban Type A group. This group is characterized by areas whose development depends mostly on locally based small- to medium-sized industries. These areas are not typically extensions of metropolitan regions (EMRs), which are defined primarily as highly urbanized areas, like the urban districts in most developing countries. The urban population of the Rural-Urban Type A group exceeded the rural population in the middle of the 1990s, while during the same period, the Rural-Urban Type B group, which actually represents the extended metropolitan regions, experienced a lower rate of urban growth, and the inhabitants were still predominantly categorized as belonging to a rural population. The data in Table 2 show that there have been more people living in urban areas in the Rural-Urban Type A group since 1980 than in other subgroups, except urban districts. Moreover, Table 2 clearly shows that the growth rate of the urban population in the Rural-Urban Type A group has been greater than that of other subgroups. Up to the year 2000, there were still more people categorized as rural than there were people categorized as urban in the Rural-Urban Type B group and, even more so, in the Rural-Urban Type C group.

Table 2. Rural and urban populations in Central Java Province in 1980, 1990 and 2000 (percent). Source: CBS [21-24].

\begin{tabular}{lcccccc}
\hline & \multicolumn{2}{c}{$\mathbf{1 9 8 0}$} & \multicolumn{2}{c}{$\mathbf{1 9 9 0}$} & \multicolumn{2}{c}{$\mathbf{2 0 0 0}$} \\
\cline { 2 - 7 } & Rural & Urban & Rural & Urban & Rural & Urban \\
\hline Central Java & 81.05 & 18.95 & 73.01 & 26.99 & 59.82 & 40.18 \\
Urban Districts & 3.98 & 96.02 & 4.61 & 95.39 & 2.38 & 97.62 \\
Rural Districts & 87.11 & 12.89 & 80.97 & 19.03 & 69.73 & 30.27 \\
Rural-Urban Type A & 77.96 & 22.04 & 58.05 & 41.95 & 36.69 & 63.31 \\
Rural-Urban Type B & 88.59 & 11.41 & 80.04 & 19.96 & 60.40 & 39.60 \\
Rural-Urban Type C & 92.91 & 7.09 & 86.88 & 13.12 & 74.85 & 25.15 \\
\hline
\end{tabular}


The Jepara, Klaten and Sukoharjo districts, classified as Rural-Urban Type A, are famous for their export-oriented wooden furniture industry. Klaten also has various marketable handicraft products, as well as developed metal industries. In addition, Kudus has been developing based on its famous cigarette industries, and its established textile and food industries have products that are marketed not only nationally, but also on an international level. All these industries are characterized primarily as small- to medium-sized industrial clusters that rely on local labor and local investment [25,26]. In contrast, the Karanganyar, Kendal and Semarang districts are classified as Rural-Urban Type B and are characterized by various types of large, foreign-based manufacturing industries.

The data in Table 2 show that rural-urban population transition in the research area takes place in the regions with potentially endogenous resources, which are not necessarily located close to the highest urban center in the hierarchy or supported by typical foreign-based industries. This is a surprising finding, as population transition in Central Java follows a different pattern than that observed in other large provinces in Indonesia. The pattern is also clearly unlike the phenomenon that has generally been observed in developing countries, as reported by Jones [27] and Douglass [28] with respect to the role of extended metropolitan regions (EMRs) in Asian countries.

Jones [27] argues that many large cities in Southeast Asia, including Indonesia, are growing very rapidly and, therefore, have experienced very rapid growth in their urban populations in the areas surrounding these cities, which are called EMRs. In these EMRs, populations are highly concentrated only in particular urban centers, which has created an unbalanced form of development pattern. This industrialization path could be described as industrialization from above. Four selected large cities in Indonesia, as illustrated in Figure 6, experienced a common pattern of population growth that is typical of most developing countries: a relatively higher population growth rate in the inner zone (closer to the capital city) than in the outer zone. Only Bandung in West Java and Semarang in Central Java have experienced relatively balanced growth in their cores, inner zones and outer zones.

Figure 6. Zones of extended metropolitan regions (EMRs) in selected large cities in Indonesia. Source: the Jakarta, Bandung, Medan and Surabaya figures are taken from Mamas et al. (2001) in Jones [27]; the Semarang figures are based on the cluster analysis results.

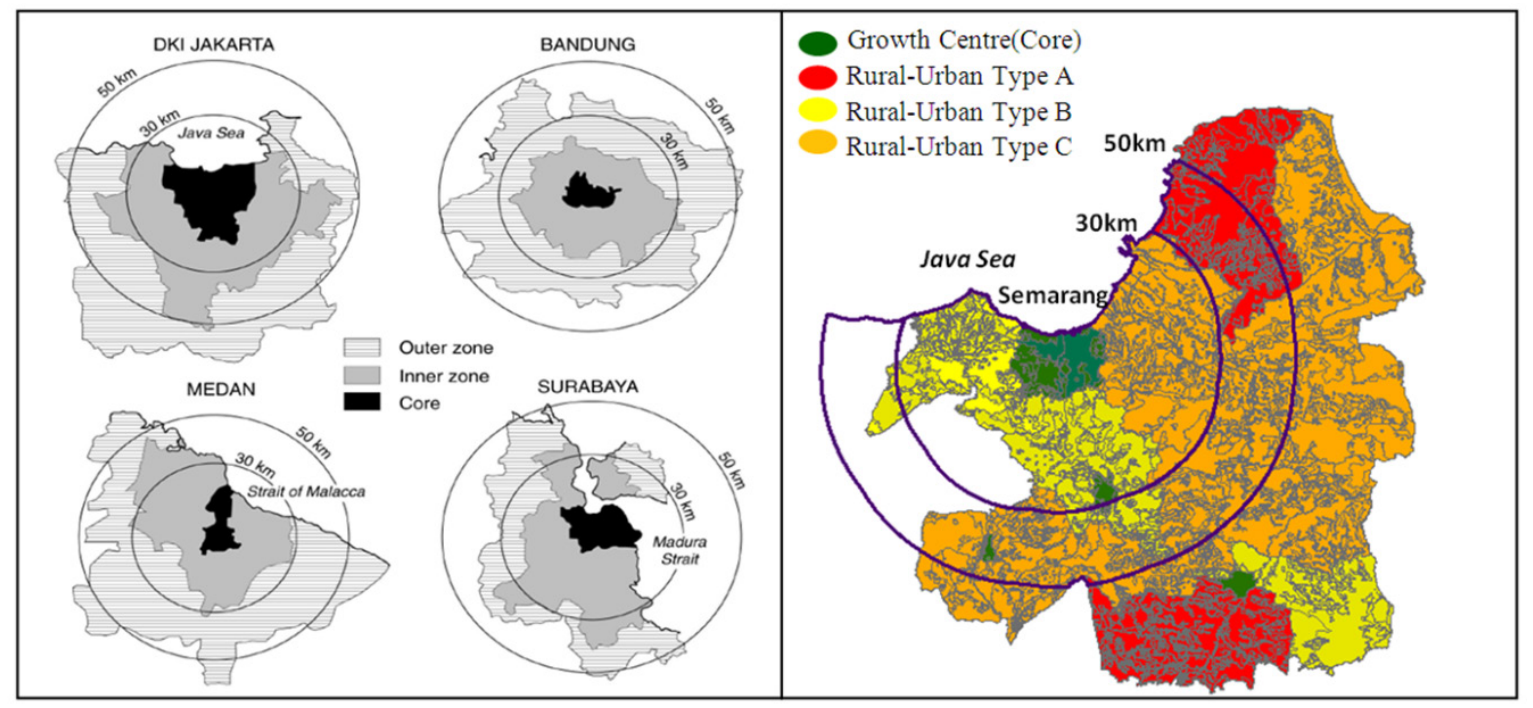


Semarang, the capital city of Central Java, has experienced relatively lower growth than other large cities in Indonesia. Furthermore, as shown in Figure 6 and Table 3, the inner zone in Central Java also experienced a lower urban population growth rate than the inner zone in four other selected large cities in Indonesia.

There are at least two factors that explain this extraordinary population growth pattern in the study area. First, the role of foreign-based manufacturing industries that are mostly located in EMRs and have led to typical industrialization from above is less dominant in Central Java than in other developed provinces in Indonesia. As a result, less labor has migrated to the surrounding core regions in the province than in most cases, because foreign-based industries attract significant numbers of laborers. This has resulted in more gradual population growth in the area. Second, endogenous resources in particular regions in the study area have acted as potential engines of growth. In this sense, it is not always true that rapid development can only occur as part of the growth of a core region, as, in fact, it has resulted in unbalanced development in most regions in developing countries.

Table 3. Rate of population growth of selected large cities in Indonesia. Source: the Jakarta, Bandung, Medan Surabaya data are taken from Mamas et al. (2001) in Jones [27]; the Semarang data are taken from CBS [21,23].

\begin{tabular}{llll}
\hline Capital City and Zone & \multicolumn{2}{c}{$\begin{array}{c}\text { Average Annual Rate of Increase (\%) } \\
\text { Onner Zone }\end{array}$} & 1.84 \\
\hline Jakarta & Core & 6.01 & 2.77 \\
Bandung & 2.08 & 2.93 & 0.89 \\
Surabaya & 2.75 & 2.50 & 0.54 \\
Medan & 1.73 & 5.46 & 0.95 \\
Semarang & 1.91 & 1.05 & \\
\hline
\end{tabular}

Note: the average values for Jakarta, Bandung, Medan and Surabaya are taken from data from 1990 and 1995; the average value for Semarang is taken from data from 1990 and 2000.

Figure 6 clearly illustrates that the development of Rural-Urban Type A areas is mostly based on more endogenous resources located relatively far from Semarang, the capital city. As the industrialization that has been taking place in these rural-urban areas has employed mostly local resources and has been located quite far from the large urban center (i.e., Semarang), the path could be defined as industrialization from below. Accordingly, the existence of this particular rural-urban region, along with the fact that Central Java has a relatively balanced average annual rate of population growth, indicates that endogenous urbanization or urbanization from below should be considered a potential form of the rural-urban transition.

\subsection{Rural-Urban Transition in Central Java Based on an Examination of Economic}

\section{Structural Changes}

Central Java Province has experienced a noteworthy economic transition over the last three decades. In 1976, the non-primary GDP exceeded the primary GDP. As shown in Table 4, in 1976, the primary GDP contributed approximately 40 percent of the total GDP, but the proportion declined significantly to only approximately 20 percent in 2006. This shows that Central Java has developed considerably 
from being dominated by agriculture to being a more industrialized province, at least as indicated by GDP contribution.

Further examination of the performance of the subgroups revealed quite different population and economic transition paths. Economic transformation has occurred at similar rates in the Rural-Urban Type A and Rural-Urban Type B areas. In fact, the GDP contribution of the non-primary sector in the Urban, Rural-Urban Type A and Type B areas surpassed the contribution of the primary sector to GDP in 1976. This indicates that rapid industrialization, as an indicator of development from an economic perspective, had taken place to a notable degree in these areas. These were the only groups of rural districts to achieve transformation in the middle of the 1970s. The Rural-Urban Type C groups, which actually were characterized as rural, did not achieve transformation until the late 1980s.

Table 4. Share of Gross domestic product (GDP) based on groups identified in the cluster analysis (percent).

\begin{tabular}{cccccc}
\hline & & $\mathbf{1 9 7 6}$ & $\mathbf{1 9 8 6}$ & $\mathbf{1 9 9 4}$ & $\mathbf{2 0 0 6}$ \\
\hline \multirow{2}{*}{ Central Java } & Primary & 41.60 & 33.86 & 24.52 & 22.20 \\
& Non-Primary & 58.40 & 66.14 & 75.48 & 77.80 \\
Urban Districts & Primary & 6.50 & 6.30 & 6.46 & 5.86 \\
& Non-Primary & 93.50 & 93.70 & 93.54 & 94.14 \\
& Primary & 50.03 & 41.70 & 38.07 & 37.28 \\
Rural Districts & Non-Primary & 49.97 & 58.30 & 61.93 & 62.72 \\
& Primary & 38.65 & 33.47 & 23.90 & 18.06 \\
Rural-Urban Type A & Non-Primary & 61.35 & 66.53 & 76.10 & 81.94 \\
& Primary & 49.46 & 41.95 & 25.16 & 19.73 \\
Rural-Urban Type B & Non-Primary & 50.54 & 58.05 & 74.84 & 80.27 \\
& Primary & 59.91 & 50.79 & 42.49 & 37.62 \\
Rural-Urban Type C & Non-Primary & 40.09 & 49.21 & 57.51 & 62.38 \\
\hline
\end{tabular}

Note: $\%$ of GDP represents the average value of each group.

Comparing Rural-Urban Type A, which represents local potential support, and Rural-Urban Type $B$, which represents the dominant role of multinational companies in the New International Division of Labor (NIDL) type of industries, it is interesting to note that the two types of regions have had similar economic transition paths. As illustrated in Table 4, between 1994 and 2006, the contributions of the non-primary and primary sectors to GDP were similar for the Rural-Urban Type A and Type B areas. It is only the growth of the non-primary sector's contribution to GDP in the Rural-Urban Type A areas that is more stable than that of the Rural-Urban Type B areas. The Rural-Urban Type B areas experienced quite rapid growth in non-primary GDP contributions between 1986 and 1994. The rate of growth then decreased slightly between 1994 and 2006, mostly due to the Asian economic crisis in the middle of the 1990s. Another finding is that the growth of the non-primary sector's GDP contribution of the rural districts was very slow, as shown in the Table 4; the non-primary GDP contribution of this subgroup was stagnant between 1994 and 2006.

With respect to the patterns observed, there are at least two important points that should be taken into account. The first point pertains to the growth pattern. The Rural-Urban Type A group experienced the steadiest growth, which indicates that external circumstances do not have a strong 
influence on local economic performance. In contrast, the growth of the Rural-Urban Type B group, which was highly dependent on external resources, was relatively unsteady. At least, a considerably slower growth rate was observed during the crisis (middle of 1990s) than during the previous period (1976-1986) and during the period after the crisis (the 2000s). The second point pertains to the contributions among the subgroups. There was a significant gap between the contribution of developed rural-urban regions (Rural-Urban Types $\mathrm{A}$ and $\mathrm{B}$ ) and that of underdeveloped regions (Rural-Urban Type $\mathrm{C}$ and rural districts). These differences are evidence of a pattern of unbalanced development in the region.

The pattern of GDP contribution is likely to be somewhat congruent with economic performance based on employment in medium and large industries. As illustrated in Figure 7, the Rural-Urban Type A groups have absorbed the largest number of employees in medium- and large-sized industries and have experienced the highest growth rates of employment in these types of industries, compared to other subgroups. During the period from 1993 to 2006, employment in medium- and large-sized industries in these rural-urban regions increased at the fastest rates, leaving behind other subgroups quite significantly. The Rural-Urban Type C group, which consists of six districts, had considerably less employment in medium- to large-sized industries than the Rural-Urban Type A group, which consists of four districts. However, it is important to note that 16 of the districts analyzed were rural, and therefore, the levels of employment in medium- and large-sized industries are higher in these districts than in Rural-Urban Type B and Rural-Urban Type C districts. In fact, the average number of people employed in these industries was only 9,600 per district in 2006, but was 31,440 for the rural-urban areas (Types A, B and C). Nevertheless, all subgroups experienced positive growth rates, which suggests that industrialization was quite significant at the provincial level.

Figure 7. Number of jobs in medium- and large-sized industries.

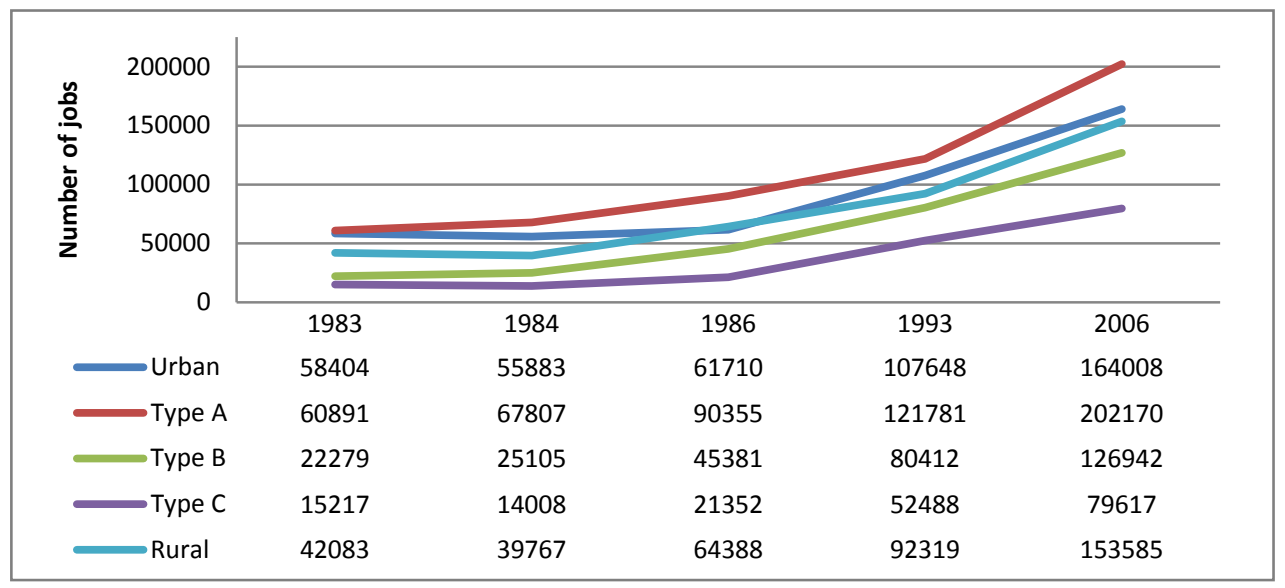

A similar trend was also observed for small industries (see Figure 8). Both the number of industries and the number of jobs indicate significant growth in Rural-Urban Type A compared to the other subgroups. Although rural districts have contributed significantly to employment in small industries, the trend is likely to decline. The number of industries in rural districts decreased from 184,360 to 160,164 , and the number of jobs decreased from 436,715 to 385,215 . A similar pattern was observed for Rural-Urban Type B. The number of industries decreased from 17,948 to 6,322, and the number of 
jobs decreased to a quarter of the 1993 level, from 40,911 to 14,501. It is clear that only the Rural-Urban Type A districts, followed by the urban districts and Rural-Urban Type C districts, exhibited relatively stable performance.

The facts reported above revealed that the Rural-Urban Type A group exhibited the steadiest growth and the smoothest economic transition, compared to the other rural-urban subgroups. One important point that should be acknowledged as a key performance factor is the dominant role of local resources, which may reduce the influence of uncontrollable external situations. Zhu [29] has reported quite similar results for Rural-Urban Type A areas in Fujian Province in China. The development of township and village enterprises (TVEs) in the province has led to what he calls "in situ urbanization". Qadeer [8] has also discussed emerging settlement systems characterized as urban being located relatively distant from urban centers in Pakistan, India and Bangladesh.

Figure 8. Numbers of industries and jobs in small industries.

\begin{tabular}{|c|c|c|c|c|}
\hline 500000 & & & & \\
\hline 400000 & & & & \\
\hline 350000 & & & & \\
\hline 300000 & & & & \\
\hline 250000 & & & & \\
\hline 200000 & & & & \\
\hline 150000 & & & & \\
\hline 100000 & & & & \\
\hline 50000 & 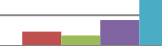 & & 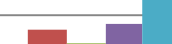 & \\
\hline & $\begin{array}{c}\text { Number of } \\
\text { Industry }\end{array}$ & Employment & $\begin{array}{l}\text { Number of } \\
\text { Industry }\end{array}$ & Employment \\
\hline & & & & \\
\hline Urban & 3211 & 15254 & 3935 & 18413 \\
\hline Type A & 24872 & 88258 & 26420 & 130552 \\
\hline Type B & 17948 & 40911 & 6322 & 14501 \\
\hline Type C & 43347 & 102021 & 37605 & 110069 \\
\hline Rural & 184360 & 436715 & 160164 & 385215 \\
\hline
\end{tabular}

With respect to Rural-Urban Type A areas, studies by Yu Zhu [29] and Qadeer [8] have also shown that small- and medium-sized enterprises (SMEs), which are mostly centered in rural areas, should be regarded as potential generators of new growth that reduce inequality among regions. Considering that SMEs are characterized as labor-intensive and that the distribution of income among enterprises is relatively more even, the dominant role of SMEs can be seen as a good sign, because it indicates a more equal income distribution. Weiss [30], Weijland [26], and Tambunan [31] believe that SMEs play a strategic function in most developing countries, as they are very important to the survival of most rural households.

\section{Conclusions}

Urbanization, which is highly correlated to the nature of rural-urban transition, has led to particular features of the rural-urban interface in Central Java. Cluster analysis shows that industrialization is a prominent indicator of the transition process, which follows at least two different paths. The first path can be described as industrialization from above, in which the transition takes place as a part of the urban growth process and is mostly the result of the development of foreign-based manufacturing 
industries. The second path can be described as industrialization from below, in which rapid (mostly locally based) industrialization leads to a particular type of urban transition that occurs far from the highest hierarchy of urban centers and is dominated by smaller-scale industries.

Districts that are categorized as rural-urban regions are located in urban fringes or as a part of the development of extended metropolitan regions. The economic activity of these districts is dominated by large manufacturing industries. Because the districts are located in favorable areas for foreign and local large investors, mostly due to the infrastructure provided and the supply of blue-collar workers, these industries do not significantly generate backward and forward linkages within the local economy. The existence of this particular type of industry has proven to be very effective in accelerating economic growth, because they contribute significantly to the regions' GDP, although they provide only a relatively small amount of employment. Indeed, the results of the cluster analysis may provide more evidence that the rural-urban transition in most developing countries does not proceed smoothly. Douglass [28] and Gilbert and Gugler [3] have expressed the belief that major cities have dominant roles, in terms of population and economic activities derived from the existence of multinational industries, in rural-urban disparities.

In contrast, industrialization from below may provide evidence that industrialization in developing countries does not necessarily always take place as part of the urban growth process or as part of extended metropolitan regional development and does not always depend on the presence of large manufacturing industries. As Zhu [29] observed in the case of in situ urbanization in Fujian Province in China and as Qadeer [8] discussed with respect to urbanization in Pakistan, India and Bangladesh, rural-urban regions, in the form of urbanization from below, are mostly located quite far from urban districts. Accordingly, the economic activity of these districts is dominated by locally based small-to medium-sized industries. This implies that these particular industries form strong local bonds. In general, these industries absorb significant numbers of workers, but unfortunately, they contribute only a small amount to the regional GDP. This means that the industries perform at a relatively low level of productivity.

Rural-urban regions characterized by industrialization from below should be acknowledged as a promising spatial form that may lead to more balanced development patterns in the future. These regions have strong local potential, which implies a stronger foundation for the economy, in addition to their ability to absorb significant numbers of people into the labor force. The form of urbanization from below observed in this research indicates that the concept of endogenous growth for developing countries is essentially down-to-earth.

\section{Acknowledgments}

This research was funded by the Directorate General of Higher Education (DGHE) of Indonesia, under its postgraduate scholarship scheme. The authors would also like to acknowledge Stefan Siedentop from the Institute of Regional Development Planning of the University of Stuttgart), and Jochen Monstadt from Spatial and Infrastructure Planning of the Technische Universität Darmstädt, for their constructive insights that improved the quality of this research. 


\section{Conflict of Interest}

The authors declare no conflict of interest.

\section{References}

1. Potter, R.B.; Binns, T.; Elliott, J.A.; Smith, D. Geographies of Development; Addison Wesley Longman: New York, NY, USA, 1999.

2. Helmsing, A.H.J. Firms, Farms and State: A Study of Rural, Urban and Regional Dimensions of Development; Kath. Hogeschool: Tilburg, Germany, 1985.

3. Gilbert, A.; Gugler, J. Cities, Poverty and Development: Urbanization in The Third World, 2nd ed.; Oxford University Press: New York, NY, USA, 1991.

4. Hansen, N.M. Development from above: The Centre-Down Development Paradigm. In Development from Above or Below? The Dialectics of Regional Planning in Developing Countries; Stöhr, W.B.; Taylor, D.R.F., Eds.; John Wiley \& Sons, Inc.: New York, NY, USA, 1981.

5. Lo, F.-C.; Salih, K.; Douglass, M. Rural-Urban Transformation in Asia. In Rural-Urban Relations and Regional Development; Lo, F.-C., Ed.; United Nations Centre for Regional Development: Tokyo, Japan, 1981.

6. Hill, H. Small and medium enterprises in Indonesia: Old policy challenges for a new administration. Asian Surv. 2001, 41, 248-270.

7. Tambunan, T. Promoting small and medium enterprises with a clustering approach: A policy experience from Indonesia. J. Small Bus. Manag. 2005, 43, 138-154.

8. Qaader, M.A. Urbanization by impolsion. Habitat Int. 2004, 28, 1-12.

9. Forbes, D. Metropolis and mega urban region in Pacific Asia. Tijdshrift voor Economische eb Sociale Geografie 1997, 88, 457-468.

10. Lynch, K. Rural-Urban Interaction in the Developing World; Routledge: London, UK, 2005.

11. Tacoli, C. The Earthscan Reader in Rural-Urban Linkages; London Institute for Environment and Development (IIED): London, UK, 2006.

12. United Nations Development Programme (UNDP). Rural-Urban Linkages: An Emerging Policy Priority; UNDP: New York, NY, USA, 2000.

13. Central Bureau of Statistics (CBS). Jawa Tengah Dalam Angka Tahun 2006 (Central Java in Figures Year 2006); CBS: Semarang, Indonesia, 2006.

14. Central Bureau of Statistics (CBS). Jawa Tengah Dalam Angka Tahun 2005 (Central Java in Figures Year 2005); CBS: Semarang, Indonesia, 2005.

15. Aldenderfer, M.S.; Roger, K.B. Cluster Analysis; Sage Publications: New York, NY, USA, 1984.

16. Everitt, B.S. Cluster Analysis, 3rd ed.; John Wiley \& Sons, Inc.: New York, NY, USA, 1993.

17. Hair, J.F.; Anderson, R.E.; Tatham, R.L. Multivariate Data Analysis. Macmilan: New York, NY, USA, 1987.

18. Hill, E.W.; Brennan, J.F.; Wolman, H.L. What is a central city in the United States? Applying a statistical techniques for developing taxonomies. Urban Stud. 1998, 35, 1935-1969.

19. Kaufman, L.; Rousseeuw, J.R. Finding Groups in Data: An Introduction to Cluster Analysis; John Wiley and Sons Inc.: New York, NY, USA, 1990. 
20. Huberty, C.J. Applied Discriminant Analysis; John Wiley \& Sons, Inc.: New York, NY, USA, 1994.

21. Central Bureau of Statistics (CBS). Penduduk Jawa Tengah Hasil Pencacahan Lengkap Sensus Penduduk 2000 (Population of Central Java, Result of The Population Census 2000); CBS: Semarang, Indonesia, 2000.

22. Central Bureau of Statistics (CBS). Statistik Indonesia 2000 (Statistical Year Book of Indonesia, 2000); CBS: Jakarta, Indonesia, 2000.

23. Central Bureau of Statistics (CBS). Penduduk Jawa Tengah Hasil Pencacahan Lengkap Sensus Penduduk 1990 (Population of Central Java, Result of The Population Census 1990); CBS: Semarang, Indonesia, 1990.

24. Central Bureau of Statistics (CBS). Penduduk Jawa Tengah Hasil Pencacahan Lengkap Sensus Penduduk 1980 (Population of Central Java, Result of The Population Census 1980); CBS: Semarang, Indonesia, 1980.

25. Handayani, W. Pengembangan sentra industri melaluli pencapaian efisiensi kolektif dalam konteks pengembangan ekonomi lokal (Industrial cluster development through collective efficiency achievement in the context of local economic development). TATALOKA 2003, 5, $17-35$.

26. Weijland, H. Microenterprise clusters in rural Indonesia: industrial seedbed and policy target. World Develop. 1999, 27, 1515-1530.

27. Jones, G.W. Southeast Asian urbanization and the growth of mega-urban regions. J. Popul. Res. 2002, 19, 119-136.

28. Douglass, M. Mega-urban regions and world city formation: Globalization, the economic crisis and urban policy issues in pacific asia. Urban Stud. 2000, 37, 2315-2335.

29. Zhu, Yu. In situ urbanization in rural China: case studies from Fujian Proviunce. Dev. Chang. 2000, 31, 413-434.

30. Weiss, J. Industrialisation and Globalization: Theory and Evidence from Developing Countries; Routledge: New York, NY, USA, 2002.

31. Tambunan, T. The role of small firms in Indonesia. Small Bus. Econ. 1992, 4, 59-77.

(C) 2013 by the authors; licensee MDPI, Basel, Switzerland. This article is an open access article distributed under the terms and conditions of the Creative Commons Attribution license (http://creativecommons.org/licenses/by/3.0/). 